\title{
PRODUCT QUALITY IMPROVEMENT USING SIX SIGMA APPROACH IN YARN MAKING PROCESS IN PT. SUTRA COTTON TEXTILE INDUSTRIES SURABAYA
}

\author{
Matias Kurnia Widyanto \\ Industrial Department, Faculty of Technology, Universitas Kartini Surabaya \\ email: superkurnia10@gmail.com
}

\begin{abstract}
The successful implementation of the six sigma quality improvement program is demonstrated through the improvement of the capability process in producing products leading to zero defect. Therefore, the concept of calculating process capability is very important to understand in the implementation of the Six Sigma program. This research raises the problem of the low level of capability process in producing yarns at PT. Sutra Cotton Textile Industries, Surabaya. By wisely applying six sigma techniques can help reduce things that can affect overall costs. If a company has successfully implemented the concepts in six sigma, then it can be ascertained that the company is truly a reliable company in the world class. Another advantage gained from the implementation of the Six Sigma program is the achievement of targets, namely the increased capability process, of course, in terms of cost. From secondary data in May 2019, in the measure phase it is known that the DPMO value of 16,266 which can be interpreted that of one million production carried out there was a defect of 16,266 with a sigma value of 3.64. From these results it can be said that the production process in Winding has not been able to produce products that fit the desired specifications and is still lagging behind other subprocesses. method. The main priority in carrying out corrective actions based on FMEA is to clean and check the machine at the end of each production cycle. From the results of improvements, the sigma value and DPMO value obtained in September 2019 is 10,977 DPMO which means that of one million production carried out there is a defect of 10,977 with a sigma value of 3.80 .
\end{abstract}

Keywords: Sigma, process, defect, product, yarn

\section{INTRODUCTION}

Along with increasingly intense competition in the industrial world, where every company both manufacturing and service companies are required to be more productive and efficient in carrying out their production processes. This is because consumers are increasingly critical in choosing a product which they assume that quality is one of the main factors for consumers in choosing a product. Today many companies are competing to get national and international recognition about their quality control management systems, such as: ICSA, ISO 9000, etc. (Hoerl and Snee, 2013). Although the operational costs incurred are quite expensive. Where they want to get satisfaction from consumers for the products used which will have a direct impact on increasing the competitiveness of these products in the market. However, the quality control management system above only emphasizes continuous improvement efforts based on personal awareness of the management, without providing effective solutions in terms of breakthroughs that must be made to dramatically improve quality towards the level of disability of the product to reach zero value (Antony and Gijo, 2016). To answer this problem, we can use the principles of Six Sigma which was first introduced and also proven by the Motorolla company, which for more than ten years has implemented the Six Sigma method and has been able to achieve 3.4 DPMO (defect per million opportunities).

Six Sigma projects must involve all parties related to the production of goods or services from the management level to the operator and have a target level of quality that will be achieved in the coming years (Mader, 2013). One of the requirements so that Six Sigma can be implemented well is that the company must really have the desire to always make continuous improvements. A company 
that wants to run a Six Sigma project well then the company must be really concerned about continuous improvement in all fields in other words the company must have the desire to always make continuous and continuous improvements. In order to be successful in implementing a Six Sigma project, there is also a need for commitment or genuine support from management and employees, especially those who are members of the Six Sigma infrastructure (Rucker, 2000).

It should be understood that capability process is a critical performance measure that shows the process is able to produce in accordance with product specifications implemented by management based on customer needs and expectations (Pande, et al, 2000). PT. Sutra Cotton Textiles Industries is a company engaged in manufacturing yarn manufacturing where the company is export-oriented so the products made are expected to be able to be oriented to international quality. This company produces various kinds of yarns, carpets and others. Defect is a serious problem faced on the production floor (Chen and Lyu, 2009). According to the information obtained the cause of the defect can be caused by machine or human error factors, in this case the operator. Faced with the fact that there is a need for action to evaluate and improve the existing process at this time, so that defects that occur can be reduced. One way to reduce the number of defects for example by improving work methods, machinery and others. The company is currently at an average level of 3 sigma. Even though the level of quality recognized by the world today is 6 sigma. Researchers feel that at this time the company being reviewed is also at a level of quality that is not much different from the average company today. For this reason a quality improvement study was conducted to help PT. Sutra Cotton Textile Industries to move towards targeted improvements, namely by carrying out systematic steps in the Six Sigma project in the company.

\section{Six Sigma Concept}

2. LITERATURE REVIEW

The basic concept of Six Sigma is to improve quality towards a zero failure rate. In other words six sigma aims to reduce the occurrence of defects in a production process with the final goal is to create a zero defect condition. Defect itself is defined as a deviation from predetermined specifications. According to Achanga, et al (2016), there are six key aspects in the application of the Six Sigma concept, namely: (1) customer identification; (2) Product identification; (3) Identification of needs in producing products for customers; (4) Definition of process; (5) Avoiding mistakes in the process and eliminating waste that occurs; (6) Continuous process improvement towards the targets in this concept.

Meanwhile, if the six sigma concept is applied in the manufacturing field, there are six aspects that must be considered, namely (Lakhavani, 2013): (a) Identification of product characteristics that will satisfy customers; (b) Classifying all quality characteristics as individual CTQ (Critical to quality); (c) Determine whether each of the CTQs can be controlled through controlling material, machinery, work processes and others; (d) Determine the maximum tolerance limits (USL and LSL values) for each CTQ as desired by the customer; (e) Determine the maximum process variation for each CTQ; (f) Changing the product and / or process design in such a way as to be able to reach the target value of six sigma, which means it has a process capability index, minimum $\mathrm{Cpm}$ is equal to two $(\mathrm{Cpm} \geq 2)$.

\section{Stages for Six Sigma}

Some stages in the sigma system can be explained as follows (Naumann, 2010):

(1) Define (D). Is an initial operational step in improving the quality of Six Sigma. At this stage the focus is on identifying products and / or processes that will be improved. The steps to be taken are (Lynch, et al, 2013): (a) Selection of six sigma research objects. The selected Six Sigma research object must be able to meet the following categories: provide business benefit results, feasibility, have a positive impact on the organization, determine the objectives of the Six Sigma research object. The statement of purpose for each true six sigma research object is to follow the SMART acronym principle as follows (Brenneman and Joner, 2012): (a) Specific; 
(b) Measurable; (c) Achievable (affordable); (d) Result-oriented (value orientation); (d) Time Bound.

(2) Measure (M)

Aiming at defining defects, gathering basic information about products or processes and eliciting improvement goals. During the measure phase there are three main things to do:

(a) Establish Key Quality
Characteristics (CTQ) Determination of key characteristics (CTQ) that are directly related to the specific needs of customers will depend on the situation and conditions of each business organization. However, we can make the determination or selection of quality characteristics of the following companies as guidelines in establishing quality characteristics (CTQ) that are in accordance with customer needs of business organizations (Koch, et $a l, 2014)$.

In carrying out the measurement of quality characteristics, basically we must pay attention to the internal and external aspects of the organization. In business organizations, internal aspects can be in the form of product defects, costs due to poor quality (cost of poor quality $=$ COPQ) such as rework, defects and others, while external aspects can be in the form of customer satisfaction, market share, etc. . In companies that have advanced usually carry out customer satisfaction research where the results of the research will be used to support top management in making strategic decisions to align the strategic goals of the company with customer desires.

(b) Baselines Performance Measurement Because the six sigma quality improvement projects implemented will focus on active efforts to improve quality towards a zero defect so as to provide total satisfaction $(100 \%)$ to customers, then before a six sigma project is started we must measure the current level of performance or in six sigma terms is called the performance baseline. After knowing the performance baseline, the improvement progress that will be achieved after starting a six sigma project can be measured throughout the six sigma project (Keim, et al, 2011).

The performance baseline in a six sigma project is usually determined using the DPMO (Defect per Million Opertunities) measurement unit and / or the sigma level (sigma level). In accordance with the usual measurement concepts applied at the process, output and outcome levels, the performance baselines can also be set at the process, output and out come levels.

$\mathrm{DPMO}=[$ Defect $/($ total unit research $\mathrm{x}$ CTQ potensial)] x $1.000 .000 \quad \ldots .(1)$

The sigma value is obtained from the DPMO conversion into the sigma value table

(3) Analyze (A)

Aims to review the data collected at the meansure stage to determine the list of causes of defects in CTQ. The steps taken are (Delgado, et al., 2010):

a. Determination of Process Stability and Capability

The six sigma program is to bring industrial processes to operate in conditions of capability and capability, so that they reach zero defect. In determining whether a process is in a stable and capable condition, we need statistical tools or methods as an analytical tool. Successful implementation of Six Sigma quality improvement programs is demonstrated through increased capability in the process of producing products leading to zero failure (zero

TiBuana, Vol. 03, No. 2, $2020 \mid 3$ 
defect). Therefore, the concept of calculating process capability is very important to understand in the implementation of Six Sigma programs. The following description will discuss techniques for determining process capabilities related to CTQ for variable and attribute data.

b. Determination of Process capability for Variable Data

The steps in determining process capability for variable data, namely (Harry and Schroeder, 2012): (a) What process you want to know; (b) Determine the upper specification limit (USL); (c) Determine the lower specification limit value (LSL); (d) Determine the target specification value (T); (e) What is the mean value; (f) What is the standard deviation $(\mathrm{S})$; (g) Calculate the possibility of defects that are above the USL value per one million opportunities (DPMO); (h) Calculate the probability of defects below the MSM value per one million opportunities (DPMO); (i) Calculate the probability of defects per DPMO produced; (j) DPMO Confirmation (step 9) into sigma values; (j) Calculate the capability of the above process in sigma measurement; (k) Calculate the process capability above in the process capability index.

\section{(4) Improve}

Aiming to optimize the solution and confirm that the offered solution will meet or exceed the objective of improvement of the research object. After the sources and root causes of quality problems are identified, it is necessary to establish an action plan to implement an improvement in the six sigma quality program (Antony, 2014). Basically the action pland will describe the allocation of resources as well as priorities and / or alternatives that are carried out in the implementation of the plan. One method of improvement is FMEA. The use of FMEA can be applied in two (2) fields, namely: in the field of design (FMEA design) and in the process field (FMEA process), but in this study the use of FMEA will be more likely to be emphasized in the process field.

\section{(5) Control (C)}

Control (C) is the last operational stage in a Six Sigma quality improvement project. At this stage quality improvement results are documented and disseminated, best practices are successful in improving standardized and disseminated processes, procedures are documented and used as standard work guidelines, and ownership or responsibility is transferred from the Six Sigma Team to the owner or the person in charge process, which means the Six Sigma project ends at this stage (Feigenbaum, 2012). The goal of standardization is to standardize a Six Sigma quality system that has proven to be the best in world class business. Satisfactory results from Six Sigma quality improvement projects must be standardized, and further improvements are made to other types of problems through other Six Sigma projects following the DMAIC concept (Johnson, 2012). Thus the Six Sigma project goals that have been achieved must be promoted to the entire organization through management and sponsors which then standardize the Six Sigma methods that have provided the optimum results.

\section{RESEARCH METHODOLOGY}

a. Preparation phase.

At this stage, the steps takenare as follows:

- Preliminary studies. By digging all theinformation from the company in this case PT. Silk Cotton Textile Industries good about the Company Description, Production Systems and so forth.

- Identification and formulation of the problem. It is important to do so that the research carried out can run as desired. Problem formulation as a first step in quality improvement research at PT. Sutra Cotton Textile Industries, where this problem was raised with the desire to improve quality to the point of zero defect. And then identify potential problems in terms of improving product quality. 
- Determine Research Objectives. After the formulation of the problem under study is carried out, then the next step is to determine the purpose of the research which will be able to provide an overview

- Literature review. Done to get theories related to problem solving.

\section{b. Stage of DMAIC}

In this study the DMAIC approach is used to solve the problems:

- Define (D). This stage is to choose the six sigmaresearch objects in the company and then determine the objectives of the six sigma research.

- Measure (M). In this measure phase what will be done is to define Critical to quality (CTQ) internal processes and identify defects and measure the number of defects that occur in relation to specific CTQs then calculate baseline performance/current performance.

- Analyze (A). The analyzing process includes determining the stability and capability of the process, identifying the sources and root causes of defects of the product under study.

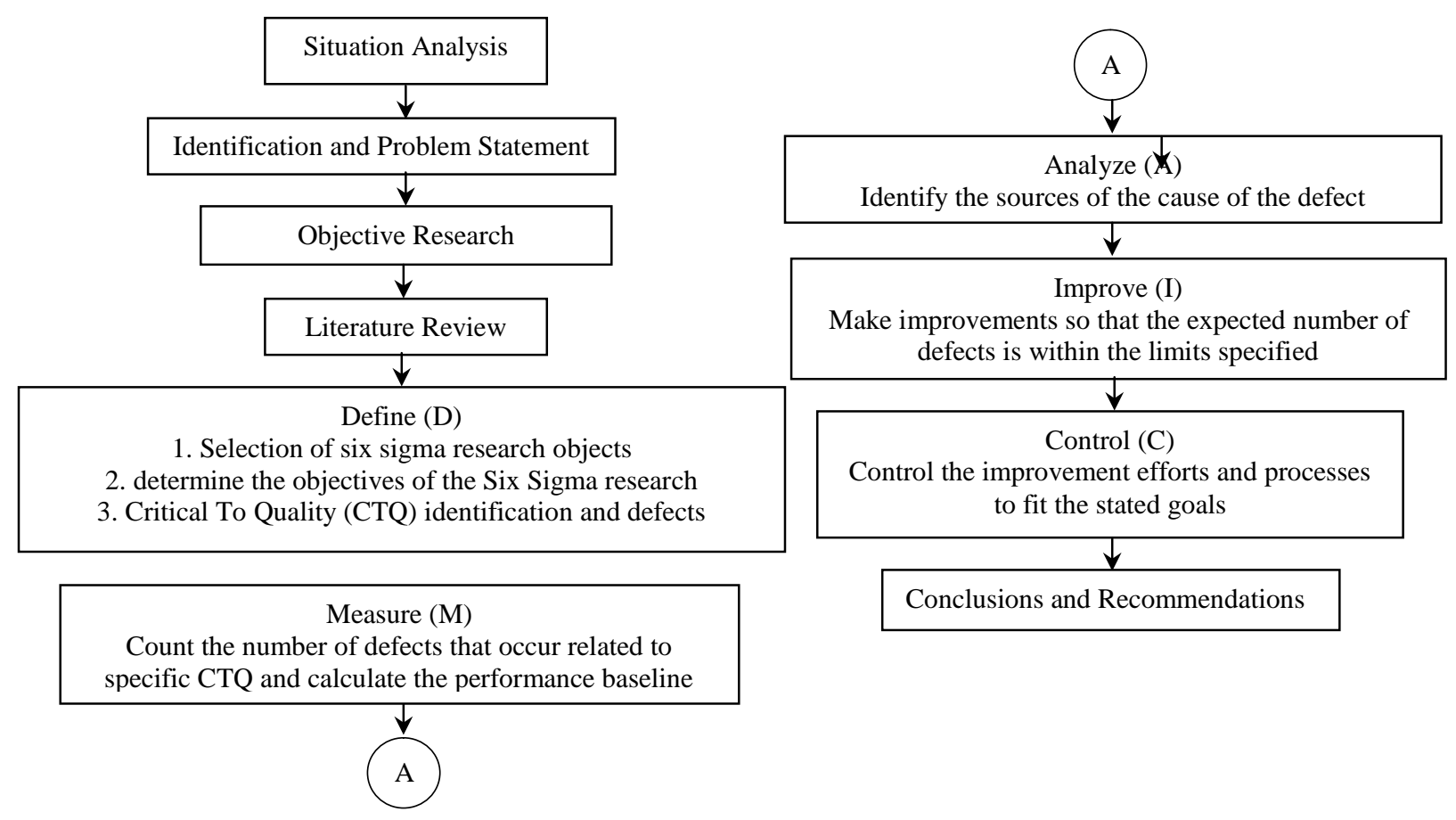

Figure 1. Research Methodology
- Improve (I). Provide methods for improvements to companies based on an analysis of the cause of the defect. Among other things by modifying internal processes so that the number of defects is within the tolerance limits that have been set previously.

- Control (C). This stage is the last operational stage in research to improve the quality of Six Sigma, where the goal is to control the improvement effort to fit the objectives. Establish a control mechanism or processes that can be modified so that the variables under control remain stable within established limits.

c. Conclusion and Suggestion Stage

- Conclusions. Is the final stage in the study,which is drawing conclusions on the measurements and quality improvements that have been made obtained from the previous steps.

- Suggestion. From the conclusion can be given suggestions that are useful for the measurement and improvement of quality that may be used as input for the company and similar research in the future.

TiBuana, Vol. 03, No. 2, $2020 \mid 5$ 
Sigma project is to reduce the level of disability arising from the Winding process which experiences the greatest level of disability in the three processes.

\section{RESULTS AND DISCUSSION}

\subsection{Define}

\section{Selection of Research Objects}

Based on information obtained from the spinning production department that the type and size of the yarn does not cause a difference in the yarn production time. Based on production data, the purpose of this Six
2.Defining the role of people interested in the Six Sigma project

In this research, a team that is more simulated than the team that the company should have in developing a DMAIC project is developed. The teams involved in the DMAIC project are as follows:

Table 1. Six Sigma Project Team

\begin{tabular}{lcl}
\hline \multicolumn{1}{c}{ Team Member } & Number & \multicolumn{1}{c}{ Authority } \\
\hline Researcher staff & 1 & Running the DMAIC flow As an authority in quality control \\
Staff quality control & 2 & As an authority in quality control \\
Production and engineering & 2 & Authorities in the engineering of the process \\
Operator & 4 & Perform production, measurement, and collect data in the field \\
\hline
\end{tabular}

1. Define Training Needs in Six Sigma Projects

The most effective Six Sigma knowledge and methodology transformation process is through a structured and systematic training system provided by groups of people involved in the Six Sigma program so that later the Six Sigma project can go according to plan. This is due to the Six Sigma organization is a learning organization. That means that the organization must continually conduct training on these new ideas or ideas.

2. Define Key Projects From Six Sigma Projects

For the Six Sigma project that has been selected, key processes must be identified. The order of the process and its interactions, as well as the customers involved in it can be identified using SIPOC diagrams (Suppliers, Inputs, Processes, Outputs, Customers). The SIPOC diagram can be seen as follows:

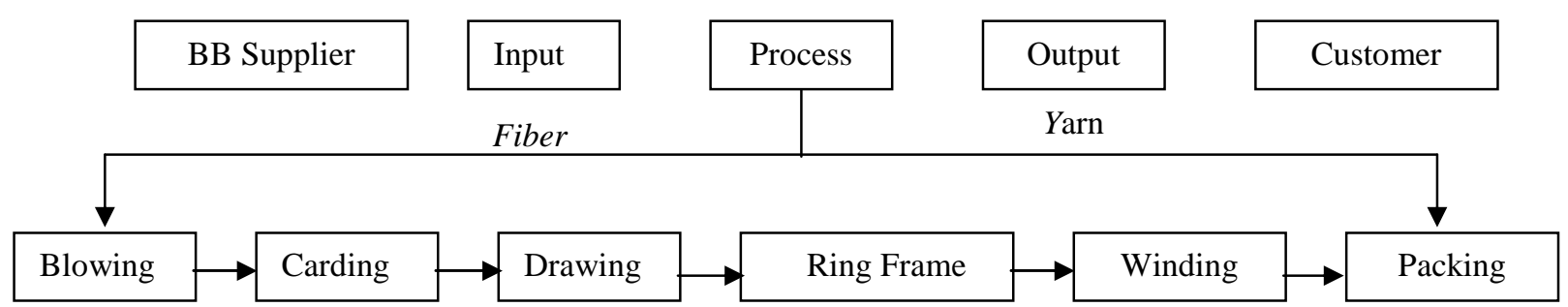

Figure 2. SIPOC Yarn Making Diagram

3. Identifying CTQ (Critical to Quality) Each product will have different criteria based on certain predetermined standards. There are two types of quality standards based on nominal and visual sizes. By visual standards, it depends on the expertise of the operator or inspection officer conducting the inspection. Similarly, the yarn produced by PT. Sutra Cotton Textile Industries which is the focus of this research. This thread is said to be good if it has certain criteria in meeting standard specifications. The quality criteria set by the company are as follows:

(a) Color. Indicates that the yarn is within certain color specifications. 
To compare the colors usedultraviolet lights.

(b) Flatness. Evenness and whether the thread is seen from the thread number. To find out it's done using the Uster Evenes Tester, the results are called $\mathrm{U} \%$ and with Wrapping Test where the test results are called CV Count $\%$. The higher the $\mathrm{U} \%$ and $\mathrm{CV} \%$, the lower the quality.

(c) Nep. Very small lumps of fiber (fiber) that can not be broken down. Nep looks like little spots and when touched with hands feels rough.

(d) Strength. Shows that the yarn has resistance to tensile testing. This is because in the process of forming yarns a lot is done so that if the strength is less then the production efficiency is low. The tools used were 2 namely lea strength namely collective testing and single strength testing itself.

(e) Cleanliness. Namely from the appearance of the thread itself as exposed to oil, and others.

(f) Roll form. Namely the state of the thread on the cone when finished rolling

(g) Jaly. Namely the neat spools but there are strands of thread coming out of the spools but are still accepted by the market.

(h) Weight. Weight of one cone at the time of weighing depends on the order.

(i) Thickness. The condition of the yarn on the roll that does not have the same diameter and also many joints.

(j) Others. In addition to the above types of kiteria quality, but rarely happens.

\subsection{Measure}

Measure is the second operational step in improving the quality of Six Sigma. At this stage a data collection plan will be carried out which will later be processed and used as a performance baseline.

1. Make a Data Collection Plan The data used in this study are historical data obtained from the PPICdepartment during the last month, namely May 2019. The data is used to calculate the value achieved by the company during May 2019.

2. Data Adequacy Test Research is valid if the data used is sufficient. with a 95\% confidence level and a 5\% accuracy level. Next is data processing for data adequacy test.

$$
\begin{gathered}
\sum X^{2}=1189^{2}+1200^{2}+\ldots \ldots+ \\
1198^{2}=42894186 \\
\sum X=1189+1200+\ldots \ldots .+1198 \\
=35872 \rightarrow\left(\sum X\right)^{2}=1286800384 \\
\mathrm{~N}^{\prime}=
\end{gathered}
$$$$
\left[\frac{\frac{k}{s} \sqrt{N\left(\sum X^{2}\right)-\left(\sum X\right)^{2}}}{\sum X}\right]^{2}=
$$$$
\left[\frac{\frac{2}{0,05} \sqrt{30(42894186)-(1286800384)}}{35872}\right]^{2}
$$

$$
=0,03133 \approx 1 \text { data }
$$

From processing the data, it is known that $\mathrm{N}^{\prime}=0.03133$ is smaller than the price of $\mathrm{N}=30$ Because the data sufficiency requirement is $\left(\mathrm{N}^{\prime}<\mathrm{N}\right)$, the data collected in this study can be said to be sufficient.

3. Performance Baseline Measurement Baseline performance measurements at the process level are carriedout directly on the Winding process. Yarn measurement data in the Winding process has been carried out for 30 times the production period. By using the SPC Wizard Sigma Calculator we will know the level of DPMO and the

TiBuana, Vol. 03, No. 2, $2020 \mid 7$ 
level of the algorithm, with the following results:

Table 2 Sigma Level Process Winding in Mei 2019

\begin{tabular}{|c|c|c|c|c|}
\hline No. & Product & Defect & DPMO & Sigma \\
\hline 1. & 1189 & 67 & 14087 & 3,70 \\
\hline 2. & 1200 & 77 & 16042 & 3,64 \\
\hline 3. & 1198 & 75 & 15651 & 3,66 \\
\hline 4. & 1195 & 75 & 15690 & 3,66 \\
\hline 5. & 1186 & 85 & 17917 & 3,60 \\
\hline 6. & 1198 & 87 & 18155 & 3,60 \\
\hline 7. & 1200 & 74 & 15417 & 3,66 \\
\hline 8. & 1196 & 68 & 14214 & 3,69 \\
\hline 9. & 1192 & 77 & 16149 & 3,64 \\
\hline 10. & 1182 & 72 & 15228 & 3,67 \\
\hline 11. & 1184 & 86 & 18159 & 3,60 \\
\hline 12. & 1198 & 68 & 14190 & 3,70 \\
\hline 13. & 1200 & 86 & 17917 & 3,60 \\
\hline 14. & 1200 & 76 & 15833 & 3,65 \\
\hline 15. & 1198 & 72 & 15025 & 3,66 \\
\hline 16. & 1200 & 81 & 16875 & 3,63 \\
\hline 17. & 1194 & 81 & 16960 & 3,63 \\
\hline 18. & 1196 & 84 & 17559 & 3,61 \\
\hline 19. & 1196 & 71 & 18841 & 3,58 \\
\hline 20. & 1184 & 72 & 15203 & 3,66 \\
\hline 21. & 1200 & 73 & 15208 & 3,66 \\
\hline 22. & 1200 & 73 & 15208 & 3,66 \\
\hline 23. & 1198 & 82 & 17112 & 3,62 \\
\hline 24. & 1196 & 86 & 17977 & 3,60 \\
\hline 25. & 1200 & 87 & 18125 & 3,60 \\
\hline $26 .$. & 1200 & 83 & 17292 & 3,62 \\
\hline 27. & 1198 & 67 & 13892 & 3,71 \\
\hline 28. & 1196 & 75 & 15677 & 3,66 \\
\hline 29. & 1200 & 83 & 17292 & 3,62 \\
\hline 30. & 1198 & 91 & 18990 & 3,58 \\
\hline Total & 35872 & 2334 & 16266 & 3,64 \\
\hline
\end{tabular}

From the calculation results in Table 2 it can be seen that the process sigma has a sigma level of 3.64 with a high enough DPMO value of 16,266 which can be interpreted that of a million opportunities there will be 16,266 chances that the product has a defect. So that it can be said that the winding process is still quite difficult to meet the desired specifications. With a Pareto diagram, the following results are obtained:

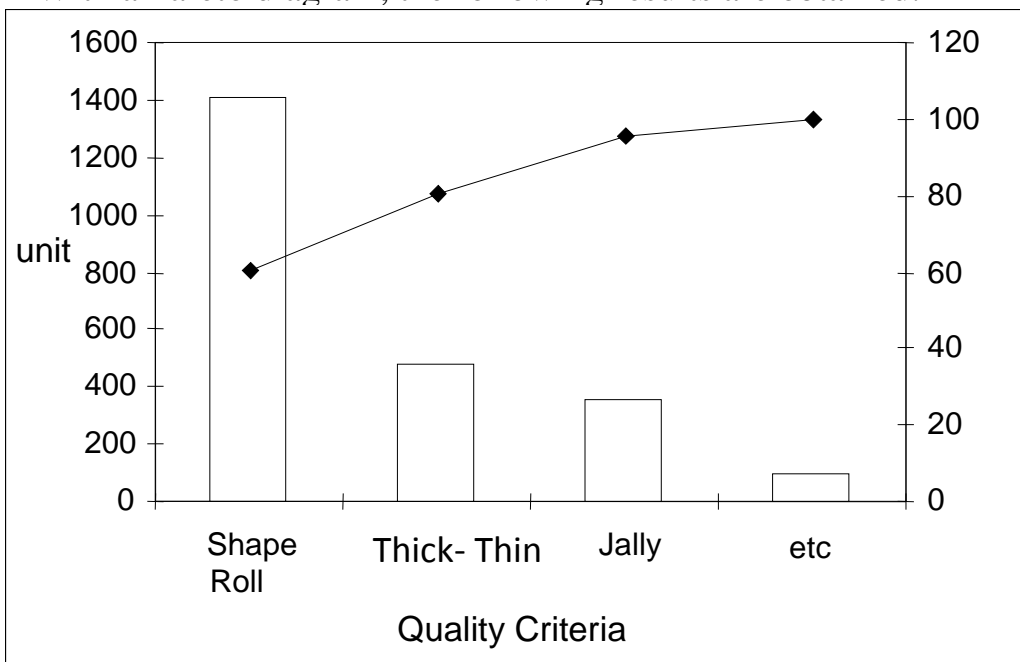

Figure 3. Pareto Diagram of Defect

Table 3. Result Pareto Analysis

\begin{tabular}{lcccc}
\hline \multicolumn{1}{c}{ Defect } & Frek. & $\begin{array}{c}\text { Frek. } \\
\text { Cumulative }\end{array}$ & $\begin{array}{c}\text { Percentage } \\
\text { from Total }(\%)\end{array}$ & $\begin{array}{c}\text { Percentage } \\
\text { Cumulative }(\%)\end{array}$ \\
\hline Shape Roll & 1408 & 1408 & 60.33 & 60.33 \\
Thick - Thin & 475 & 1883 & 20.35 & 80.68 \\
Jally & 353 & 2236 & 15.12 & 95.80 \\
etc & 98 & 2334 & 4.20 & 100.00 \\
Total & 2334 & - & 100.00 & - \\
\hline
\end{tabular}

From the Pareto diagram above, it can be seen that the roll shape provides the largest contribution to the total defect that occurs in Winding by $66.24 \%$. So that the focus of repairs that will be done is on the quality criteria for the shape of the roll.

\subsection{Analyze}

8 | TiBuana, Vol. 03, No. 2, 2020
Analysis is the third stage of the DMAIC cycle. At this stage an analysis of sigma values will be carried out in the winding process and identifying the sources of the defect by brainstorming with the company, namely the production department using the Cause and Effect Diagram. Identification of the sources of deviations in the shape of the yarn. This step is done by brainstorming with 
the company, namely the production

Diagram tool, it is obtained. department. By using the Cause and Effect

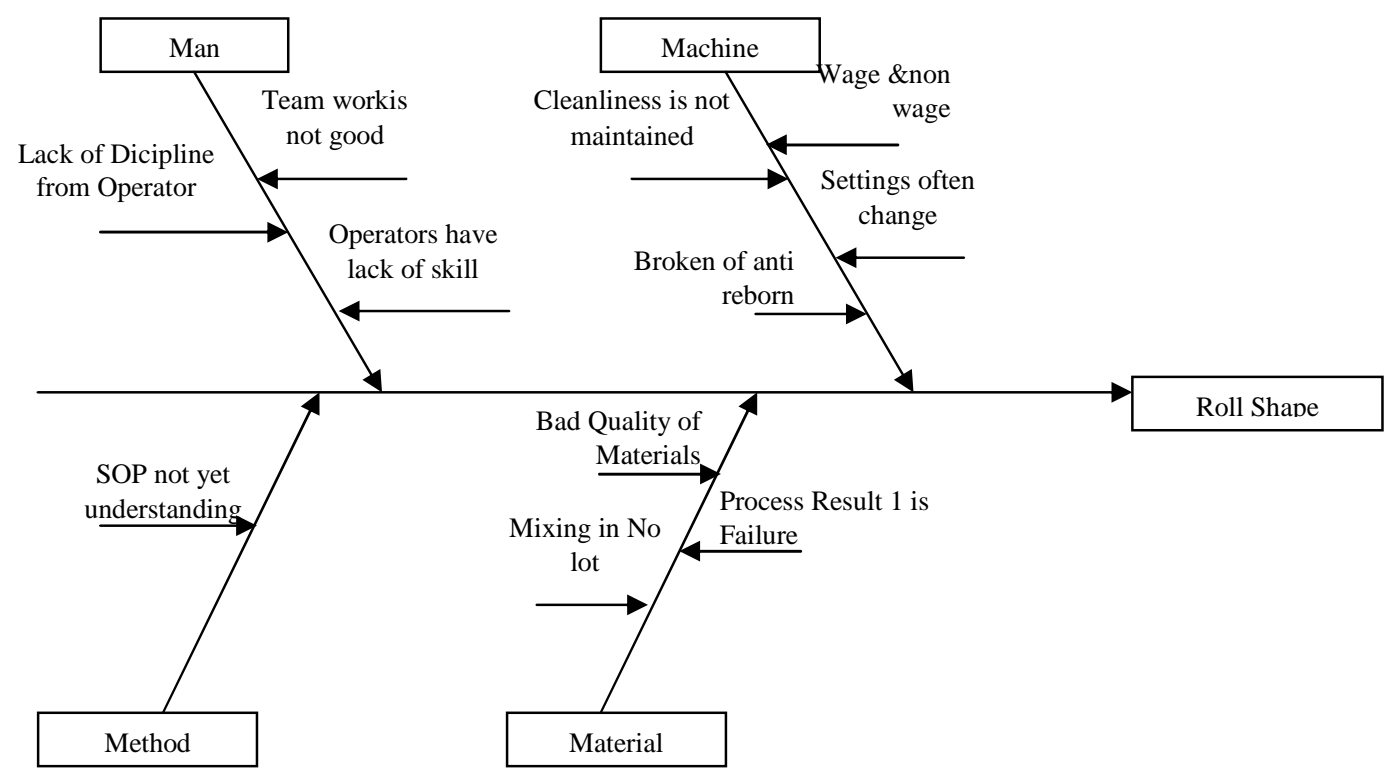

Figure 4.Cause Effect Diagram

\subsection{Improve}

In this study, it was found that the limits of not doing experiments in making improvements, so that at the Improve tool stage used was FMEA. FMEA is done by brainstorming with the production department that is the Winding process, wherein in this section the parties are competent and know the process well. From the alternative actions available, the ranking is carried out as a corrective action that will be done based on the cause of the failure. This ranking is obtained by using FMEA based on the existing values, namely severity, occurance, and detectability. Using a score of 1-10, on each factor for each potential problem.

\section{Table 4. Priority Corrective Actions}

\begin{tabular}{ccl}
\hline Priority & RPN & Proposed Corrective Action \\
\hline 1 & 280 & Cleaning \& checking is done after every one production cycle \\
3 & 256 & Supervisors are more aware of the process 1 checking officer (ring frame) \\
& 224 & $\begin{array}{l}\text { The ring frame operator is more closely monitored and distinguishes the color of } \\
\text { the bobbin which can distinguish the number from the yarn }\end{array}$ \\
& 224 & Give warning and reprimand so as not to make mistakes in control \\
4 & 224 & Provide maintenance training and direction \\
5 & 196 & Training and understanding of the actions taken \\
6 & 168 & Cleaning and engine speed are lowered \\
& 147 & Provides understanding to operators and maintenance \\
7 & 90 & Provide training and direction to operators before they start work \\
8 & 72 & Checked when the material comes \\
\hline
\end{tabular}

\subsection{Control}

Control phase is the final stage of the DMAIC cycle. Where at this stage the process of monitoring will be carried out to find out whether improvements have been made to increase the value of sigma or not. Based on the improvements made in September 2019, the next calculation is done using the SPC 
Wizard's Calculator Sigma and the following results are obtained:

Table 5. Sigma Levels of Winding Processes in September 2019

\begin{tabular}{ccccc}
\hline No. & Production & $\begin{array}{c}\text { Number } \\
\text { of Defect }\end{array}$ & DPMO & Sigma \\
\hline 1. & 1196 & 55 & 11497 & 3,78 \\
2. & 1199 & 52 & 10842 & 3,80 \\
3. & 1198 & 58 & 12104 & 3,76 \\
4. & 1200 & 49 & 10208 & 3,82 \\
5. & 1200 & 52 & 10833 & 3,80 \\
6. & 1198 & 46 & 9599 & 3,85 \\
7. & 1200 & 59 & 12292 & 3,75 \\
8. & 1189 & 57 & 11985 & 3,76 \\
9. & 1195 & 52 & 10879 & 3,80 \\
10. & 1197 & 53 & 11069 & 3,79 \\
11. & 1196 & 45 & 9406 & 3,85 \\
12. & 1198 & 54 & 11269 & 3,79 \\
13. & 1199 & 47 & 9800 & 3,84 \\
14. & 1199 & 56 & 11676 & 3,77 \\
15. & 1194 & 53 & 11097 & 3,79 \\
16. & 1196 & 52 & 10870 & 3,81 \\
17. & 1200 & 49 & 10208 & 3,82 \\
18. & 1198 & 52 & 10851 & 3,80 \\
19. & 1200 & 55 & 11458 & 3,78 \\
20. & 1200 & 49 & 10208 & 3,82 \\
21. & 1199 & 53 & 11051 & 3,79 \\
22. & 1196 & 48 & 10033 & 3,83 \\
23. & 1199 & 49 & 10217 & 3,82 \\
24. & 1200 & 53 & 11042 & 3,79 \\
25. & 1192 & 52 & 10906 & 3,80 \\
26. & 1196 & 54 & 11288 & 3,79 \\
27. & 1193 & 57 & 11945 & 3,76 \\
28. & 1195 & 58 & 12134 & 3,76 \\
29. & 1198 & 53 & 11060 & 3,79 \\
30. & 1196 & 55 & 11497 & 3,78 \\
Total & 35916 & 1577 & 10977 & 3,80 \\
\hline & & & & \\
\hline
\end{tabular}

\section{CONCLUSION AND RECOMMENDATION}

\subsection{Conclusion}

Some conclusions that can be drawn from the results of this study are as follows:

1. From the historical data for May 2019, in themeasure phase it is known that the DPMO value is 16,266 which can be interpreted that of one million production carried out there is a defect of 16,266 with a sigma value of 3.64. From these results it can be said that the production process at
From the analysis of the data after the above improvements we can compare at the beginning of the study which is used as a performance baseline like the following table:

Table 6. Comparison of DPMO and Sigma Values

\begin{tabular}{ccccc}
\hline No. & \multicolumn{2}{c}{ Mei 2019} & \multicolumn{2}{c}{ September 2019} \\
& DPMO & Sigma & DPMO & Sigma \\
\hline 1. & 14087 & 3,70 & 11497 & 3,78 \\
2. & 16042 & 3,64 & 10842 & 3,80 \\
3. & 15651 & 3,66 & 12104 & 3,76 \\
4. & 15690 & 3,66 & 10208 & 3,82 \\
5. & 17917 & 3,60 & 10833 & 3,80 \\
6. & 18155 & 3,60 & 9599 & 3,85 \\
7. & 15417 & 3,66 & 12292 & 3,75 \\
8. & 14214 & 3,69 & 11985 & 3,76 \\
9. & 16149 & 3,64 & 10879 & 3,80 \\
10. & 15228 & 3,67 & 11069 & 3,79 \\
11. & 18159 & 3,60 & 9406 & 3,85 \\
12. & 14190 & 3,70 & 11269 & 3,79 \\
13. & 17917 & 3,60 & 9800 & 3,84 \\
14. & 15833 & 3,65 & 11676 & 3,77 \\
15. & 15025 & 3,66 & 11097 & 3,79 \\
16. & 16875 & 3,63 & 10870 & 3,81 \\
17. & 16960 & 3,63 & 10208 & 3,82 \\
18. & 17559 & 3,61 & 10851 & 3,80 \\
19. & 18841 & 3,58 & 11458 & 3,78 \\
20. & 15203 & 3,66 & 10208 & 3,82 \\
21. & 15208 & 3,66 & 11051 & 3,79 \\
22. & 15208 & 3,66 & 10033 & 3,83 \\
23. & 17112 & 3,62 & 10217 & 3,82 \\
24. & 17977 & 3,60 & 11042 & 3,79 \\
25. & 18125 & 3,60 & 10906 & 3,80 \\
26. & 17292 & 3,62 & 11288 & 3,79 \\
27. & 13892 & 3,71 & 11945 & 3,76 \\
28. & 15677 & 3,66 & 12134 & 3,76 \\
29. & 17292 & 3,62 & 11060 & 3,79 \\
30. & 18990 & 3,58 & 11497 & 3,78 \\
Tota.1 & 16266 & 3,64 & 10977 & 3,80 \\
\hline & & & & \\
\hline
\end{tabular}

products that fit the desired.

2. Based on the FMEA analysis, the most influential causes of the roll shape are the human, machine, material and method factors.

3. The main priority in taking corrective actions based on FMEA is to clean and check the machine after each production cycle.

4. From the results of improvement, the sigma value and DPMO value obtained in September 2019 is 10,977 DPMO which means that of one million production 
carried out there is a defect of 10,977 with a sigma value of 3.80 .

\subsection{Recommendation}

Suggestions that can be given by researchers are as follows:

1. For further research, it should be done in all subprocesses so that the research results can describe the overall process state.

2. 2. Experiments should be carried out in order to obtain better results in accordance with the specified target value.

3. the next researcher, it should also be carried out a discussion about losses experienced in financial terms and also in terms of employee job satisfaction.

\section{REFERENCES}

1. Achanga,P.,Shehab,E.,Roy,R.and Nelder,G. (2016). Critical success factors for lean implementation within SMEs. Journal of Manufacturing Technology Management, Vol. 17 No. 4, pp. 460-471.

2. Antony, J. (2014). Six Sigma in the UK service organizations: results from a pilot survey. Managerial Auditing Journal, Vol. 19 No. 8, pp. 1006-1013

3. Antony,J.,Rodgers,B.and Gijo,E.V. (2016). Can Lean Six Sigma make UK public sector organisations more efficient and effective?. International Journal of Productivity and Performance Management, Vol. 65 No. 7, pp. 9951002.

4. Brenneman, W.A. and Joner, M.D. (2012). Setting appropriate fill targets-a statistical engineering case study. Quality Engineering, Vol. 24 No. 2, pp. 241-250.

5. Chen, M. and Lyu, J. (2009). A Lean SixSigma approach to touch panel quality improvement. Production Planning \& Control, Vol. 20 No. 5, pp. 445-454.

6. Delgado, C., Ferreira, M. and Branco, M.C. (2010). The implementation of Lean Six Sigma in financial services organizations. Journal of Manufacturing
Technology Management, Vol. 21 No. 4, pp. 512-523.

7. Feigenbaum, A.V. (2012).Total Quality Control, 3rd ed. McGraw-Hill, Inc.New York.

8. Harry, M.J. and Schroeder, R.R. (2012). Six Sigma: The Breakthrough Management Strategy Revolutionizing the World's Top Corporations. Currency Publishers. New York.

9. Hoerl, R.W. and Snee, R.D. (2013). One size does not fit all: identifying the right improvement methodology. Quality Progress, May, pp. 48-50.

10. Johnson, A. (2012). Six Sigma in R\&D. Research Technology Management, Vol. 45, No. 2, pp.12-17.

11. Keim, E., Fox, L. and Mazza, J.S. (2011). Service quality Six Sigma case studies. Annual Quality Congress Proceedings. Milwaukee, pp.188-193.

12. Koch, P.N., Yang, R.J. and Gu, L. (2014). Design For Six Sigma through robust optimization. Structural and Multidisciplinary Optimization, Vol. 26, Nos. 3-4, pp.235-248.

13. Lakhavani, S.T. (2013). Six Sigma implementation: trials, tribulations and lessons learned. Annual Quality Congress ProceedingsMilwaukee, pp.643-647.

14. Lynch, D.P., Bertolino, S. and Cloutier, E. (2013). How to scope DMAIC projects. Quality Progress, Vol. 36, No. 1, pp.3741

15. Mader, D.P. (2013). DFSS and your current design process. Quality Progress, Vol. 36, No. 7, pp.88, 89.

16. Naumann, E. (2010). Customer centered Six Sigma. Annual Quality Congress Proceedings, Milwaukee, pp.631-640.

17. Pande P. Neuman R. y Cavanagh R. (2000). The Six Sigma Way: How GE, Motorola and Other Top Companies are Honing Their Performance. Mc Graw Hill. USA.

18. Rucker, R. (2000). Citibank increases customer loyalty with defect-free processes. Journal of Quality and Participation, Vol. 23, No. 4, pp.32-37. 